\title{
Qualitative Data Analysis: An Overview of Data Reduction, Data Display and Interpretation
}

\author{
Esubalew Aman Mezmir \\ Lecturer at Wolkite University, Department of Sociology
}

\begin{abstract}
This paper intends to present the practical aspects of doing qualitative data analysis. To this end, the paper was compiled to understand the practical aspects of doing qualitative data analysis with the ultimate purpose of identifying the commonly used approaches and techniques for data reduction, data display, and interpretation. Secondary source of data was used to collect and analyze the data needed to address the aforementioned objectives. Accordingly, books, articles, research reports, and different published materials were critically reviewed. The paper began by defining what qualitative data analysis is in accordance with its aim, basic principles and features. In addition, the paper presents qualitative data analysis and its philosophical foundations on the basis of ontological and epistemological stance. The paper further discuss the most commonly used approaches to analyze qualitatively collected data focusing on the background and philosophical basis of each method, unique characteristics of each method, goals and rationale of each method and data analysis process of each method. The paper has also disclosed ethical issues to be considered on the process of qualitative data analysis. The arguments on the paper have by and large proved to be very helpful for analyzing qualitatively collected data in the domain of humanities and social Science inquiries.
\end{abstract}

Keywords: Qualitative Data Analysis, Data Reduction, Data Display, and Data Interpretation.

DOI: $10.7176 /$ RHSS/10-21-02

Publication date: November $30^{\text {th }} 2020$

\section{Introduction}

Collecting information, which researchers call data, is only the beginning of the research process. Once collected, the information has to be organized and thought about. Material collected through qualitative methods is invariably unstructured and bulky. A high proportion of it is text based, consisting of verbatim transcriptions of interviews or discussions, field notes or other written documents. Moreover, the internal content of the material is usually in detailed and micro form (e.g. accounts of experiences, descriptions of interchanges, observations of interactions, etc.). Therefore, the qualitative researcher has to provide some coherence and structure to this bulky data set while retaining a hold of the original accounts and observations from which it is obtained. Besides, qualitative data analysis is concerned with transforming raw data by searching, evaluating, recognizing, coding, mapping, exploring and describing patterns, trends, themes and categories in the raw data, in order to interpret them and provide their underlying meanings. The methods used for qualitative analysis therefore need to facilitate such detection, and to be of a form which allows certain functions to be performed (Bryman and Burgess, 1994).

To this effect, the central focus of this paper is to show practical aspects of doing qualitative data analysis focusing on data reduction, data display and interpretation. It attempts to identify the philosophical foundations to do qualitative data analysis. It also tries to outline basic steps and approaches in analyzing qualitative data. The paper ends with giving a bird view point on the issue of ethics in doing qualitative data analysis.

\subsection{Definition of Qualitative Data Analysis}

Qualitative data analysis is the classification and interpretation of linguistic (or visual) material to make statements about implicit and explicit dimensions and structures of meaning-making in the material and what is represented in it. Meaning-making can refer to subjective or social meanings. Qualitative data analysis could also be applied to discover and describe issues in the field or structures and processes in routines and practices. Often, qualitative data analysis combines approaches of a rough analysis of the material (overviews, condensation, summaries) with approaches of a detailed analysis (elaboration of categories, hermeneutic interpretations or identified structures). The final aim is often to arrive at generalizable statements by comparing various materials or various texts or several cases (Bryman, 2001).

\subsection{Aims of Qualitative Data Analysis}

According to Uwe Flick (2009), the analysis of qualitative data can have several aims. The first aim may be to describe a phenomenon in some or greater detail. The phenomenon can be the subjective lived experiences of a specific individual or group (e.g. the way people continue to live after displacing from home land). This could focus on the case (individual or group) and its special features and the links between them. The analysis can also focus on looking interplay of several cases (individuals or groups) and on what they have in common or on the differences between them. The second aim may be to explore the conditions on which the existing differences are 
based. This means to look for explanations of the observed differences (e.g. circumstances which make it more likely that the coping with a specific social disarticulation is more successful than in other cases). The third aim may be to develop a theory of the phenomenon under study from the analysis of empirical material (e.g. a theory of displacement).

\section{Philosophical Foundations behind Qualitative Data Analysis Process}

According to Kuhn (1970), a paradigm is basic set of beliefs that guide action, whether of the everyday garden variety or action taken in connection with a disciplined inquiry. Hence, paradigms shape research at its most basic level; worldviews frame the types of questions asked and what the answers might look like. Parallel to this, research can be understood as arising from particular paradigms that inform particular perspectives. Besides, theoretical perspectives are the philosophical stance informing the methodology and thus providing a context for the process and grouping its logic and criteria. Therefore, every research process is shaped by paradigmatic assumptions and principles and concepts described in theoretical perspectives.

The quest to come up with the meaning and analyzing our qualitative data cannot be successful without the basic knowledge of philosophical stance (i.e. the ontological and epistemological assumptions). According to Mason (2002), Ontology and Epistemology are words very commonly used within academia. They further posits that ontology is concerned with the question of "What is there?", while epistemology is concerned with the questions "What do you know?" and "How do you know it?" hence, both act as foundations to analyze our data. As a result, considering the influence of ontology and epistemology on qualitative data analysis process has given the paper a wider scope to explore the philosophical foundation behind analyzing qualitative data.

\subsection{The Influence of Ontology on Qualitative Data Analysis Process}

According to Corbetta (2003) Ontology is a philosophical pattern of view in research, it is the science or study of being and it deals with the nature of reality. They further explain Ontology as a belief system that indicates the way in which an individual interprets what represent a fact. In other words, Ontology is concerned with the central question of whether social entities need to be perceived as objective or subjective. This view is consistent with the opinion of Bryman (2001), who conceive that Ontology is intended to explain the nature of social entities. This implies that Ontology describes the nature of reality from the researcher's view or being on the societal organization which the phenomenon is studied.

Moreover, identification of the ontology at the begging of research process is critically important as it determines the choice of the research design to be adopted via epistemology, which affects the research approach as well as the research strategy, methods of data collection and data analysis. This methodology, in turn, will be influenced by the theoretical perspectives adopted by the researcher, and, in turn, by the researcher's epistemological stance.

To this effect, while doing qualitative data analysis, ontologically we have to stick on the grounding principles and basic features of subjectivism school of thoughts and its philosophical stance.

\subsubsection{Subjectivism School of Thought}

Subjectivism school of thought also described as interpretivism or social constructivism. It generally attempts to understand the complex nature of social reality. Subjectivism as a school of thought argues that the researcher and the phenomenon under study are mutually interrelated and dependent. This school of thought draws attention to the researcher openness to new knowledge throughout the study and to let the reality understudy be develop with the help of study participants. The use of such an emergent and collaborative approach is consistent with the interpretivist belief that humans have the ability to adapt, and that no one can gain prior knowledge of time and context bound social realities. Therefore, the goal of interpretivist research is to understand and interpret the meanings in human behavior rather than to generalize and predict causes and effects. Besides, the conclusions are derived from the interpretations of data gathered from the participants rather than the abstract theories of the researcher or scientist (David and Felix, 2003).

The subjectivism school of thought share one basic principle; namely that the impossibility of making objective statement about the real world because there is no such thing as a real world but it is only socially and discursively constructed. Therefore, there is no social reality that can exist independently of our interpretation and every observation concomitantly affects what we observe (David and Felix, 2003).

\subsection{The Influence of Epistemology on QDA Process}

Epistemology can be defined as the relationship between the researcher and the reality or how this reality is captured or known (Corbetta, 2003). Hence, epistemology is concerned with the questions of "What do you know?" and "How do you know it?" Furthermore, epistemology is the claim on what knowledge is valid in research, and therefore what constitutes acceptable sources of evidence (presenting that knowledge) and acceptable end results of knowledge (findings).

Trying to make clarity to epistemological philosophy Scotland (2012) posits that epistemology is concerned 
with the nature and forms of knowledge. In other words, epistemological assumptions are concerned with how knowledge can be created, acquired and communicated. Bateson (1951), revealed that, "epistemology" means the theory of knowledge, the study of the nature of knowing, and the branch of philosophy which has grown up around the word is intertwined with ontology, the study of the nature of being. He further states that the very meaning of the word "epistemology" was changed from the conventional. He argued that the study of knowing or the study of "information" is inseparable from the study of communication, codification, purpose, and values.

Therefore, in the process of conducting qualitative data analysis we have to give great emphasis on how our study participants create realities about the issues understudy, how their world is determined by the way they see it and how they function within it.

\subsection{Basic Principles of Qualitative Data Analysis}

According to Bryman and Burgess (1994) there are basic principles of qualitative data analysis. These are mentioned below:

$>$ People differ in their experience and understanding of reality (Constructivist-many meanings).

$>$ A social phenomenon can't be understood outside its own context (Context-bound).

$>$ Qualitative research can be used to describe phenomenon or generate theory grounded on data.

$>$ Understanding human behavior emerges slowly and non-linearly.

$>$ Exceptional cases may yield insights into a problem or new idea for further inquiry.

\subsection{Basic Features of Qualitative Data Analysis}

Bryman and Burgess (1994) further explained the basic features of qualitative data analysis. These are mentioned below:

$>$ Analysis is circular and non-linear.

$>$ Iterative and progressive.

$>$ Close interaction with the data.

$>$ Data collection and analysis is simultaneous.

$>$ Level of analysis varies.

$>$ Uses inflection.

$>$ Can be sorted in many ways.

$>$ Qualitative data by itself has meaning.

\subsection{Stages to Analyze Qualitative Data}

There are no universally agreed stages in the process of analyzing qualitative data. Different authors mentioned different stages in order to analyze qualitative data. For instance, Scott and Scott \& Usher (2004) conceived that a typical qualitative analytical approach to consist five stages. However, Bryman \& Burgess (1994) argue that analysis of qualitative data has to follow six stages. Moreover, Creswell (2009), contrary to the view of Bryman \& Burgess (1994), believes that the process of qualitative data analysis and interpretation can best be represented by a spiral image, a data analysis spiral, in which the researcher moves in analytic circles rather than using a fixed linear approach.

Therefore, there are always variations in the number and description of steps for doing qualitative data analysis by different authors. To this effect, I prefer to review different sources describing steps to analyze qualitative data and adopt the most possible steps from each. To this end, the process of qualitative data analysis consists of four stages (steps), namely: Familiarization, Data Reduction, Data Display, and Report Writing. The details of these analytical stages are described and illustrated as follows.

\subsubsection{Familiarization}

Before beginning the process of filtering and sorting data, the researcher must become familiar with their variety and diversity of material gathered. Even if the researcher own does not collect the data, it is must to form feeling about key issues and emergent themes in the data by considering the context.

Essentially, familiarization involves concentration in the data: listening to tapes, reading transcripts, studying observational notes and so on. According to Bryman and Burgess (1994) in some cases it is possible to review all the material at the familiarization stage, for example where only a few interviews have been carried out, or where there is a generous timetable for the research. They further outline number of features in the data collection process and points to be depend on while selecting the material to be reviewed, such as:

$>$ The range of methods used

$>$ The number of researchers involved

$>$ The diversity of people and circumstances studied

$>$ The time period over which the material was collected

$>$ The extent to which the research agenda evolved or was modified during that time

NOTE: When making a selection, it is important to ensure that a range of different cases, sources, and time periods 
are reviewed.

\subsubsection{Identifying a Thematic Framework}

In the familiarization stage, the researcher is not only gaining an overview of the richness, depth, and diversity of the collected data, but also he/she starts the process of abstraction and conceptualization. While reviewing the material, the researcher is expected to make notes, record the range of responses to questions posed by the researchers themselves, jot down frequent themes and issues which emerge as important to the study participants themselves.

As Bryman and Burgess (1994) mentioned, once the selected material has been reviewed, the researcher returns to these research notes, and attempts to identify key issues, concepts and themes according to which the data can be examined and referenced. That is, she or he sets up a thematic framework within which the material can be filtered and sorted. When identifying and constructing this framework or index, the researcher will be drawing upon a priori issues such as:

$>$ Issues informed by the original research aims and introduced into the interviews using the topic guide

$>$ Emergent issues raised by the respondents themselves

$>$ Analytical themes arising from the recurrence or patterning of particular views or experiences

\subsubsection{Data Reduction}

It is very likely that qualitatively captured research project is going to generate more data than its final write up. However, engaging in data reduction process is very helpful in order to edit the data, summarize it, and make it presentable. Therefore, we have to reduce our data to make things more manageable and evident. According to Huberman and Miles (1994) with data reduction, the potential universe of data is reduced in an anticipatory way as the researcher chooses a conceptual framework, research questions, cases, and instruments. Once actual field notes, interviews, tapes, or other data are available, data summaries, coding, finding themes, clustering, and writing stories are all instances of further data selection and condensation. From the very possible ways to reduce and organize data in qualitative study, this paper attempts to look in to coding of qualitative data, writing memos, and mapping concepts graphically. Hence, these ideas give a useful starting point for finding order in qualitative data.

\subsubsection{Coding}

Saldana (2013) has argued that coding does not constitute the totality of data analysis, but it is a method to organize the data so that underlying messages portrayed by the data may become clear to the researcher. Charmaz (2006) describes coding as the pivotal link between data collection and explaining the meaning of the data. A code is a descriptive construct designed by the researcher to capture the primary content or essence of the data. Coding is an interpretive activity and therefore it is possible that two researchers will attribute two different codes to the same data. The context in which the research is done, the nature of the research and interest of the researcher will influence which codes the researcher attributes to the data (Saldana, 2013). During the coding process, some codes may appear repeatedly and that may be an indication of emerging patterns. These emerging patterns or similarity among the codes may give rise to categories. Coding is not only labeling, but also linking, that is, linking data to an idea. It is a cyclic process. By incorporating more cycles into the coding process, richer meanings, categories, themes and concepts can be generated from the data (Saldana, 2013).

\subsection{Practical Aspects of Coding}

Saldana (2013) gives a practical guide for the coding process. He mentioned that it is helpful to type the data on the left two-thirds of a page and to leave the right margin open for notes. Whenever the topic of the data seems to change, the researchers can start a new paragraph. In writing down the data, researchers need to decide whether they want to give a verbatim transcription of the interviews for their specific study. Saldana (2013) further explains the importance of reading the data, to do some 'pre-coding' by circling, highlighting or underlining significant words or sentences. However, different authors urge researchers to start the coding process whilst they are collecting the data, keeping in mind that the codes may change during later cycles. Saldana (2009) suggests that researchers should keep their research questions and aims of their studies in mind. The following questions may assist them in their coding decisions:

$>$ What are people doing? What are they trying to accomplish?

$>$ Exactly how are they doing it? What strategies are they using?

$>$ How do they talk about, characterize and understand what is going on?

$>$ What assumptions are they making?

What is going on here? What do I, as researcher, learn from these notes? What strikes me?

These questions correspond with aspects, that might be coded, namely activities or behavior, events, strategies or tactics, present situations, meanings, participation, relationships or interactions, conditions or constraints, consequences, settings and the researcher's own reflections.

The number of codes, Saldana (2013) states, depends on the context, the nature of the data and to what degree of fineness the researcher wants to examine the detail. Data can be 'lumped' together with a single code or can be 'split' into many smaller parts, each bearing its own code. Both methods have advantages and disadvantages. Even though splitting is time-consuming, it may produce a more nuanced analysis. On the other hand, lumping gets to 
the essence of categorizing, although it may produce superficial analysis. The number of codes may change during a second cycle of Saldana (2013) advises that the initial coding should be done on hard copies, although electronic resources are available, as hard copies tend to give a better perspective.

\subsection{Writing Analytic Memos: Concurrently with coding}

According to Saldana (2013) the analytic memos document how the coding process is developing and codes may trigger deeper reflection on the side of the researcher on the meaning of the data. It is important that researchers write down their insights. Analytical memos give researchers the opportunity to reflect and comment on the following:

$>$ How they personally relate to the participants and the phenomenon;

$>$ Their research questions;

$>$ The code choices;

$>$ Emergent patterns and categories;

$>$ Problems and ethical dilemmas in the study; and

$>$ The future direction for the study.

Writing analytical memos can be seen as the transitional phase from coding to the more formal writing of the report on the study. The analytical memos can also be coded and categorized and may even lead to better codes or categories for the data (Saldana, 2013).

\subsection{Useful Coding Methods for Qualitative Data}

Saldana (2013) mentions that grounded theory, one of the approaches in qualitative research, has six coding techniques in its coding catalog. Researchers normally use these coding methods during two coding cycles. During the first cycle, the data is split into segments then; in vivo coding, process coding and initial coding may be used. During the second cycle, researchers compare codes, note emerging patterns and reorganize the data into categories by using the focused, axial and theoretical coding techniques. Despite the fact, that these techniques are mentioned for grounded theory, it is important to note that researchers can use these coding methods also in non-grounded theory studies (Saldana, 2013).

\section{A. In vivo Coding}

This method of coding is useful for beginner qualitative researchers, as the exact word or phrase of the participant serves as a code. In order to distinguish in vivo codes, the researchers put them between inverted commas. The researchers look for words or phrases that seem to stand out, for example nouns with impact, action-orientated verbs, evocative word choices, clever phrases or metaphors. In vivo coding can be the only coding method used during the first cycle of data analysis, but it may be limiting (Saldana, 2013).

\section{B. Process (Action) Coding}

A process code is a word or a phrase that captures action. It is done by using gerunds ('-ing' words) as part of the code. Process coding is useful to identify an on-going action as a response to situations, or an action to handle a problem, or to reach a goal. As a process code usually conveys movement and shows how things have changed over time, it helps the researchers to give a dynamic account of events. It conveys a path of the participant's process (Saldana, 2013).

\section{Initial (Open) Coding}

Initial coding refers to the process of breaking the qualitative data down into distinct parts and coding these by using in vivo coding, process coding, and other coding methods. The researchers then examine these parts closely and compare them for similarities and differences. During this process, the researchers may already become aware of emerging categories and code them. It is important to remember that initial codes and categories are tentative and may change as the analysis process progresses. After initial coding, the researchers need time for reflection by means of the writing of analytical memos (Saldana, 2013).

\section{Focused Coding}

Saldana (2013) explains that after initial coding, the researchers gets on focused coding by identifying the most frequent or significant codes in order to develop the prominent categories (it is linked to axial coding). He warns that the researchers should be aware that these categories do not always have well-defined boundaries and that the codes in a specific category may have different degrees of belonging. Rubin and Rubin (quoted by Saldana, 2013) recommend that the researchers organize the categories hierarchically in main categories and subcategories in order to understand the relationship between them.

\section{E. Axial Coding}

The goal of axial coding is the strategic reassembling of data that have been split during initial coding. In the process of crossing out synonyms and redundant codes, the dominant codes will become apparent. The axis of the axial coding is a category. During axial coding, categories are related to subcategories and the properties and dimensions of a category are specified (Saldana, 2013). Central categories describe the key properties of the phenomenon, causal categories capture the circumstances that form the structure of the studied phenomenon, strategies describe the actions or interactions of people in response to the phenomenon, and consequential categories represent the outcomes of the actions or interactions. Thus, through axial coding, the researchers will 
be able to answer when, where, why, who, how and with what consequences questions (Saldana, 2013).

\section{F. Theoretical (Selective) Coding}

It is the process to select the theoretical code or core category that functions like an umbrella that covers all codes and categories. It relates to all categories and subcategories. It addresses the how and why questions to explain the phenomena. However, this is not necessary for every qualitative study (Saldana, 2013).

\subsubsection{Memoing}

In qualitative data analysis approaches, particularly in grounded theory, the coding process involves more than simply categorizing large pieces of text. As you code data, you should also be using the technique of memoing, writing memos or notes to yourself and others involved in the study. Some of what you write during analysis may end up in your final report; much of it will at least excite what you write. In many qualitative data analysis approaches, these memos have a special significance. Strauss and Corbin (1998) distinguish three kinds of memos: code notes, theoretical notes, and operational notes.

\section{A. Code Notes}

It is useful to identify the code labels and their meanings. This is particularly important because, as in all qualitative studies, most of the terms we use with technical meanings also have meanings in everyday language. Hence, it's essential, to write down a clear account of what you mean by the codes used in your analysis (Strauss \& Corbin, 1998).

\section{B. Theoretical Notes}

It tries to cover a variety of topics such as, reflections of the dimensions and deeper meanings of concepts, relationships among concepts, theoretical propositions, and so on. All of us have reflected over the nature of something, trying to think it out, to make sense out of it. In qualitative data analysis, it's vital to write down these thoughts, even those you'll later discard as useless. They will vary greatly in length, though you should limit them to a single main thought so that you can sort and organize them later (Strauss \& Corbin, 1998)

\section{Operational Notes}

It deals primarily with methodological issues. Some will draw attention to data collection circumstances that may be relevant to understand the data later on. Others will consist of notes directing future data collection (Strauss \& Corbin, 1998).

Generally speaking, writing these memos occurs throughout the data collection and analysis process. Thoughts demanding memos will come to you as you reread notes or transcripts, code mass of text, or discuss the project with others. It's a good idea to get in the habit of writing out your memos as soon as possible after the thoughts come to you.

Notice that whereas we often think of writing as a linear process, starting at the beginning and moving through to the conclusion, memoing is very different. It might be characterized as a process of creating chaos and then finding order within it.

\subsubsection{Concept Mapping}

It should be clear by now that qualitative data analysts spend a lot of time committing thoughts to paper (or to a computer file), but this process is not limited to text alone. Often, we can think out relationships among concepts more clearly by putting the concepts in a graphic format, a process called concept mapping. Some researchers put all their major concepts on a single sheet of paper, whereas others spread their thoughts across several sheets of paper, blackboards, magnetic boards, computer pages, or other media (Strauss \& Corbin, 1998).

\section{Displaying Data in Qualitative Studies}

Hubeman and Miles's (1994) notion of data display roughly involves using textual representations of your data for the purpose of selecting segments that best illustrate your concepts of interest. Typically, this includes the following:

$>$ Carefully reading and rereading data transcriptions

$>$ Making notes in the margins (sometimes referred to as 'research memos')

Highlighting important passages or themes as representations of particular concepts.

The objective is to gradually transform a seemingly disorganized raw data into a recognizable conceptual scheme. For most sociologists, the medium of choice for display and selection purposes is paper; however, some might be more comfortable viewing their data on a computer screen. In fact, there are some computer software programs, such as NUD*IST or NVivo, that allow you to draw diagrams and write research memos on the margins of your computer screen.

\section{Drawing Conclusions}

This last step in the analysis involves making meaningful statements about how your data illustrates your topic of interest. As Huberman and Miles (1994) note, this step involves 'drawing meaning from displayed data'. The word 'drawing' should be taken quite literally here: you draw the relevant meaning, structure or processes out of the data based on the type of analysis you choose. 
What meanings should be drawn from the analysis? The answer depends on your disciplinary orientation. For example, we recognize certain studies as being sociological based on the way the researchers made sense of their data, or the particular meanings they drew from their data using a sociological orientation.

In the following pages, I attempt to discuss an overview of a number of approaches to analyze qualitative data with an emphasis on sociological interpretations.

\section{Approaches To Analyze Qualitative Data}

Using an appropriate research method for inquiry is critical to successful research. To this end, in this section I attempts to discuss the most commonly used methods to analyze qualitatively collected data in Sociological inquire (i.e. Grounded Theory, Qualitative Content Analysis, Conversation Analysis, and Discourse Analysis). In so doing; background and philosophical basis, unique characteristics of each method, goals and rationale of each method and data analysis process of each method have been discussed. Hence, it will provide knowledge that can assist researchers in the selection of appropriate research methods to analyze qualitative data.

\subsection{Grounded Theory}

\subsubsection{Background and Philosophical Basis of Grounded Theory}

The term grounded theory was introduced in The Discovery of Grounded Theory (1967) by Glaser and Strauss as "the discovery of theory from data, systematically obtained and analyzed in social research". Instead of verification of theories, they introduced a research method to arrive at a "theory suited to its supposed uses" contrasting with a "theory generated by logical deduction from a priori assumptions". According to Strauss and Corbin (1994) it is "a general methodology, a way of thinking about and conceptualizing data".

According to Glaser and Strauss (1967) grounded theory works as a method as well as a methodology. Crotty (2003) has described methodology as the strategy, plan of action, process, or design in doing research, while he defines method as the techniques or procedures used to gather and analyze data.

The bid to grounded theory was a reaction to positivism, which followed a scientific falsification and verification. Glaser and Strauss (1967) suggested that a researcher can achieve a theory that is meaningful in certain contexts from observations and the observers' consensus (Suddaby, 2006). Furthermore, as Groat \& Wang (2002) mentioned grounded theory involves the use of an intensive, open-ended, and iterative process that simultaneously involves data collection, coding (data analysis), and memo-writing (theory building).

The conceptual orientation of grounded theory resembles that of symbolic interactionism, which is based on the belief that human beings are acting rather than just responding beings and that human action is purposeful and based on the meanings that the individual has for them. Inherent in the symbolic interactionism is the position that "meaning is negotiated and understood through interactions with others in social processes" (Priest et al., 2002).

\subsubsection{Unique Characteristics of Grounded Theory}

Grounded theory has two unique characteristics: constant comparative analysis and theoretical sampling. On the one hand, constant comparative analysis entails an iterative process of concurrent data collection and analysis, which involves the systematic choice and study of several comparison groups. Therefore, the researcher does not wait until data are completely collected to begin data analysis; instead, data collection and analysis occur simultaneously so that the analyzed data guides subsequent data collection. Furthermore, during the data analysis process, an incident should be compared and contrasted with other incidents. Researchers need to make comparisons between empirical data and concept, between concept and categories, among data and categories in order to reach higher levels of abstraction and advance with the conceptualization. The purposes of comparative analysis are to obtain accuracy of evidence in the conceptual category and to establish the generality of a fact (Glaser \& Strauss, 1967).

On the other hand, theoretical sampling is the process of collecting data for comparative analysis, which means insight from initial data collection and analysis leads to subsequent data collection and analysis. It involves recruiting participants with differing experiences of the phenomenon so as to explore multiple dimensions of the social processes under study. Therefore, during analysis, researchers must be theoretically sensitive to the data analysis that guides them toward what to do next (Glaser \& Strauss, 1967).

\subsubsection{Research Goals and Rationale for Using Grounded Theory}

According to Strauss \& Corbin (1994) researcher who uses grounded theory aims to generate a substantive theory that will explain a phenomenon in a specific context and suited to its supposed use. The emphasis in grounded theory is theory development. Thus, grounded theory is appropriate when no theory exists or when a theory exists that is too abstract to be tested, but it is not appropriate for the test of a theory or generation of knowledge from objective reality.

\subsubsection{Data Analysis Process in Grounded Theory}

Data analysis in grounded theory was originally introduced by Glaser and Strauss (1967) as a method of constant comparative analysis; they proposed that constant comparative analysis consists of explicit coding and analytic procedures and suggested the following four procedures of data analysis: 
1. Comparing incidents applicable to each category

2. Integrating categories and their properties

3. Delimiting the theory and

4. Writing the theory

Corbin and Strauss (1990) explained coding as the process of concept labeling and categorizing. They considered the concept as a basic unit of analysis. Then, concepts with the same phenomena can be grouped into a category. Besides, coding is also described as categorizing segments of data with a short name that simultaneously summarizes and accounts for each piece of data and as the pivotal link between collecting data and developing an emergent theory to explain these data. Through coding, the researcher seizes the meaning of the data.

Harry, Sturges, and Klingner (2005) summarized the following six stages as the analysis level of grounded theory approach:

1. Open coding

2. Conceptualizing categories

3. Developing themes

4. Testing the themes

5. Interrelating the explanations

6. Delineating the theory

Figure 1: Data analysis procedure of grounded theory method.

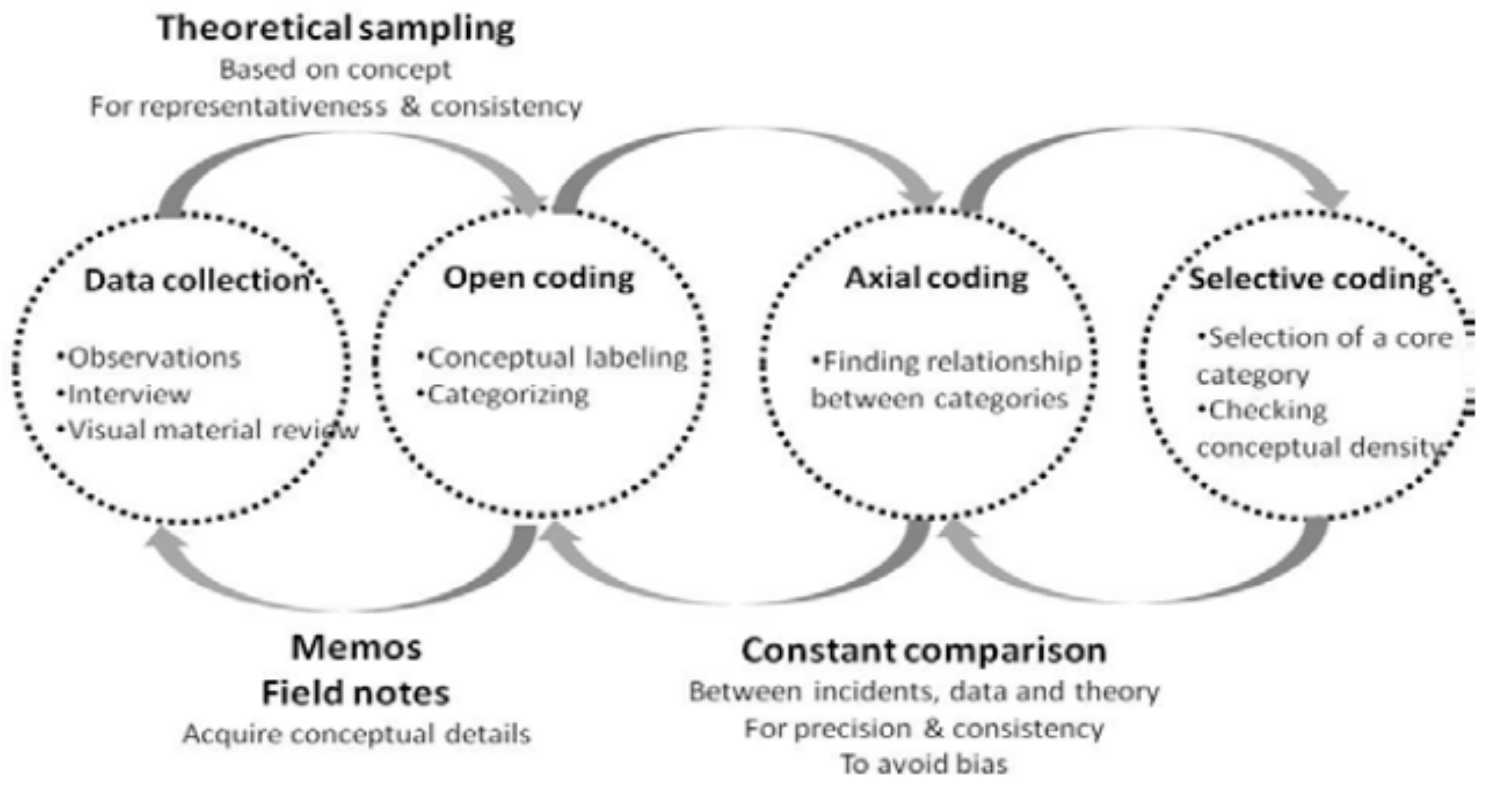

Source: adapted from Harry et al. (2005)

\subsection{Qualitative Content Analysis}

\subsubsection{Background and Philosophical Basis of Qualitative Content Analysis}

According to Berelson (1952) the early definition of content analysis shows that it started as a quantitative research method. It was defined as research technique for the objective, systematic, and quantitative description of the manifest content of communication. Moreover, Abrahamson (1983) asserted that content analysis can be fruitfully used to examine virtually any kind of communication materials, including narrative responses, open-end survey questions, interviews, focus groups, observations, printed media such as articles, books, or manuals (as cited in Hsieh \& Shannon, 2005). Because researchers can engage in data collection with or without direct contact with persons studied, it can be an unobtrusive method.

Content analysis was first used as an analytic technique at the outset of the 20th century for analyzing textual materials from newspaper, magazine, articles, political speeches, and advertisements. It was primarily used as a quantitative research method to analyze the content of media text to enable similar results to be established across a group of text coders (Priest et al., 2002).

The quantitative approach in content analysis was criticized, however, because it often simplified and distorted meaning as a result of breaking down text into quantifiable units in the analytic process. As a result, Kracauer (1952) advocated a qualitative approach to content analysis, in which meanings and insights can be derived from the text more holistically (Priest et al., 2002).

Qualitative content analysis can be referred to as "a research method for subjective interpretation of the 
content of text data through the systematic classification process of coding and identifying themes or patterns" (Hsieh \& Shannon, 2005). Therefore, it is a method for systematically describing the meaning of qualitative material.

\subsubsection{Unique Characteristics of Qualitative Content Analysis}

One unique characteristic of qualitative content analysis is the flexibility to use inductive or deductive approaches or a combination of both approaches in the data analysis process. Second is the ability to extract manifest and latent content meaning (Elo \& Kyngas, 2008).

First, qualitative content analysis is flexible in the use of inductive and deductive analysis of data depending on purpose of the study. The key difference between the two approaches centers on how initial codes or categories are developed. On the one hand, an inductive approach is appropriate when prior knowledge regarding the phenomenon under investigation is limited or fragmented. In the inductive approach, codes, categories, or themes are directly drawn from the data (see figure 2 below), whereas the deductive approach starts with preconceived codes or categories derived from prior relevant theory, research, or literature (see figure 3 below). On the other hand, the deductive approach is appropriate when the objective of the study is to test existing theory or retest existing data in a new context (Elo \& Kyngas, 2008).

Second, coding in qualitative content analysis can give emphasis on the manifest as well as the latent content meaning of communications. Whereas manifest content means the researcher codes the visible and surface content of text, latent content means that the researcher codes the underlying meaning of the text. Often the researcher wishes to reach beyond the manifest content of the text and analyze latent content (Graneheim \& Lundman, 2004). Schreier (2012) argued qualitative content analysis as being suitable for data that require some degree of interpretation.

Figure 2: Procedure for a deductive approach to qualitative content analysis.

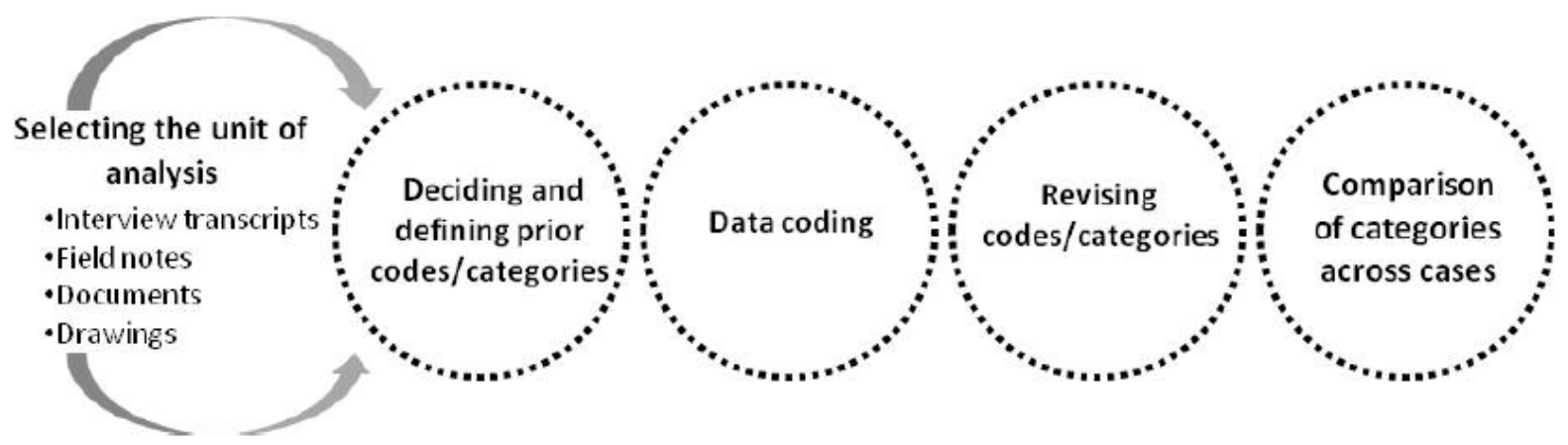

Source: adapted from Elo \& Kyngas (2008)

Figure 3: Procedure used in an inductive approach to qualitative content analysis.
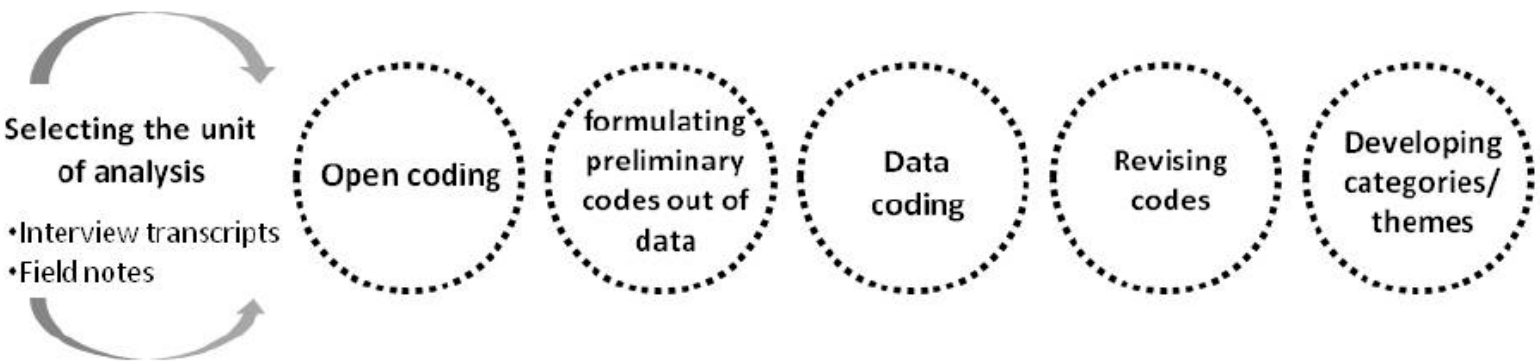

Source: adapted from Elo \& Kyngas (2008)

5.2.3. Research Goals and Rationale for Using Qualitative Content Analysis

According to Schreier (2012) a researcher who uses qualitative content analysis aims to systematically describe the meaning of materials in a certain respect that the researcher specified from research questions. Although, qualitative content analysis follows coding processes, it does not focus on finding relationships among categories or theory building; instead, it focuses on extracting categories from the data.

\subsubsection{Data Analysis Process in Qualitative Content Analysis}

Compared to grounded theory, the procedures required in qualitative content analysis have not been well articulated in the literature (Cavanagh, 1997); however, Mayring's (2000) steps have provided clarification. Mayring (2000) proposed two different procedures for qualitative content analysis according to researchers' approaches: inductive category development and deductive category development. Inductive category development consists of:

A. The research question, 
B. The determination of category and levels of abstraction,

C. The development of inductive categories from material,

D. The revision of categories,

E. The final working through text, and

F. The interpretation of results.

In deductive category development, every step indicated for inductive category development is applied; however, the second and third steps are different (i.e. theoretical-based definitions of categories and theoreticalbased formulation of coding rules).

Overall, according to Crowley \& Delfico (1996) the process of data analysis includes the following core steps: selecting the unit of analysis, creating categories, and establishing themes. Selecting the units of analysis is an important initial step as a means to data reduction. Therefore, researchers should decide which data will be analyzed by focusing on a selected aspect of material depending on the research questions.

Creating categories is a means to compress a large number of texts into fewer content-related categories. A category refers to items with similar meaning and connotations. It must be mutually exclusive and exhaustive, and no data should fall between two categories or be placed in more than one category. In addition, enough categories to accommodate important contents must be created. Researchers should determine how best to categorize data because data often lack a single meaning or interpretation (Cavanagh, 1997).

Establishing a theme is a way to link the underlying meanings together in categories. As Streubert \& Carpenter (1995) has explained further the concept of a theme as holding multiple interpretations. Besides, it is a way to describe a structural unit of meaning essential to present qualitative results, a recurring regularity identified within or cutting across categories and an expression of the latent content of the text (Graneheim \& Lundman, 2004).

\subsection{Conversation Analysis}

Conversation analysis is less interested in interpreting the content of texts that have been produced for research purposes, for instance interview responses. Rather it is interested in the formal analysis of everyday situations. The theoretical background of conversation analysis is ethno-methodology. This approach is mainly suits to studies aimed at exploring members' formal procedures for constructing social reality. To do this, empirical material is selected to collect data, involved in recording everyday interaction processes as precisely as possible.

Bergmann (2004a) outlines this approach, as follows:

Conversation Analysis refers to a research approach dedicated to the investigation of social interaction as a continuing process of producing and securing meaningful social order. Conversation analysis proceeds on the basis that in all forms of linguistic and non-linguistic, direct and indirect communication, actors are occupied with the business of analyzing the situation and the context of their actions, interpreting the expression of their own action, producing situational appropriateness, intelligibility and effectiveness in their own expression. The goal of this approach is to determine the constitutive principles and mechanisms by means of which actors, in the situational completion of their actions and in reciprocal reaction to their action, create the meaningful structures and order of a sequence of events and of the activities that constitute these events. In terms of method Conversation analysis begins with the richest possible documentation, with audio-visual recording and subsequent transcription of real social events, and breaks these down into individual structural principles of social interaction as well as the practices used to manage them by participants in an interaction.

To this effect, emphasis is placed less on the analysis of the contents of a conversation and more on the formal procedures through which the contents are communicated and certain situations are produced.

Schegloff and Sacks (1974) in explaining closings in conversations, they have mentioned three assumptions in doing conversation analysis. Thus are:

1. Conversation analysis assumes that interaction proceeds in an orderly way and nothing in it should be regarded as random.

2. The context of interaction not only influences this interaction but also is produced and reproduced in it.

3. The decision about what is relevant in social interaction and thus for the interpretation can only be made through the interpretation.

\subsubsection{The Procedure of Conversation Analysis}

Ten Have (1999) suggests the following four steps for research projects using conversation analysis as a method:

1. Getting or making recordings of natural interaction

2. Transcribing the tapes, in whole or in part

3. Analyzing selected episodes

4. Reporting the research

According to Flick (2009) conversation analysis has two basic features. An essential feature of conversation analytic interpretation is the strictly sequential procedure (i.e., ensuring that no later statements or interactions are consulted for explaining a certain sequence). Rather, the order of the occurrence must show itself in understanding 
it sequentially. The turn-by-turn production of order in the conversation is clarified by an analysis, which is oriented to this sequence of turns. Another feature is the emphasis on context. This means that the efforts in producing meaning or order in the conversation can only be analyzed as local practices; that is, only related to the concrete contexts in which they are embedded in the interaction and in which the interaction again is embedded (e.g., institutionally).

Therefore, conversation analysis and the empirical results that have been obtained by applying it attempts to explain the social production of everyday conversations and specific forms of discourse. The results document the linguistic methods that are used in these discourses. Furthermore, they show the explanatory strength of the analysis of natural situations and how a strictly sequential analysis can provide findings which accord with and take into account the compositional logic of social interaction.

\subsection{Discourse Analysis}

As Flick (2009) has argued discourse analysis has been developed from different backgrounds, one of which was conversation analysis. The theoretical background of discourse analysis is social constructionism. It focuses on how the making of social reality can be studied in discourses about certain objects or processes.

According to Silverman (1993) discourse analytic studies analyze issues that are closer to the topics of social sciences than those of conversation analysis. They combine language analytic proceedings with analyses of processes of knowledge and constructions without restricting themselves to the formal aspects of linguistic presentations and processes. Moreover, conversation analysis is named as a starting point; its empirical focus is more on the content of talk, its subject matter, and with its social rather than linguistic organization. This allows the analysis to be embedded in social domains. Parker (2004) suggests a number of steps in the research process to conduct discourse analysis. Thus are:

1. The researcher should turn the text to be analyzed into written form, if it is not already.

2. Free association to varieties of meaning as a way of accessing cultural networks, and these should be noted down.

3. The researchers should systematically itemize the objects, usually marked by nouns, in the text or selected portion of text.

4. They should maintain a distance from the text by treating the text itself as the object of the study rather than what it seems to "refer" to.

5. Then they should systematically itemize the subjects (i.e. characters, persona, and role-positions), specified in the text.

6. They should reconstruct presupposed rights and responsibilities of subjects specified in the text.

7. Finally, they should map the networks of relationships into patterns. These patterns in language axe "discourses," and can then be located in relations of ideology, power, and institutions.

\section{Ethics and Qualitative Data Analysis}

Flick (2009) has mentioned, at least two ethical issues cause special concern in the analysis and reporting of qualitative research.

First, because it calls so directly on subjective judgments, researchers face an obvious risk of seeing what they are looking for or want to find. Researcher bias is hardly inevitable; however, experienced qualitative analysts avoid this difficulty through a deliberate awareness of their own values and preferences as well as adherence to established techniques for data collection and analysis. And as an additional protection, the peer review inherent in the scientific research environment encourages colleagues to point out any failings in this regard.

Second, protecting subjects' privacy becomes a particularly important issue in qualitative research. The qualitative researcher will often analyze and report data collected from specific, identifiable individuals. When writing up the results of your analyses, you will often have to actively hide identities. To this effect, Individuals, organizations, and communities are given pseudonyms to hide their identities. Sometimes, you may even need to suppress details that would let outsiders figure out who you are talking about. Thus, it may be appropriate to speak about interviewing "a church leader" rather than "the head deacon." The key principle is to respect the privacy of those we study.

\section{Conclusion}

Many rich descriptions of social phenomena in Sociological studies are accomplished best with qualitative approaches. Many qualitatively oriented studies questions with the goal of understanding a socially constructed reality. To this effect, while doing qualitative data analysis, ontologically we have to stick on the grounding principles and basic features of subjectivism school of thoughts and its philosophical stance. Besides, epistemologically we have to give great emphasis on how our study participants create realities about the issues understudy, how their world is determined by the way they see it and how they function within it.

Data collection and analysis are inseparable, and common sources of data include interviews, observations, 
and documents. The analysis process of qualitatively collected data is embedded in data reduction, data display, and interpretation. Common techniques used for data reduction in qualitative inquiries include; coding of collected data, writing memos, and mapping concepts graphically. Data display in qualitative study involves using textual representations of your data for the purpose of selecting segments that best illustrate your concepts of interest. Careful reading and rereading data transcriptions, writing research memos, and highlighting important passages or themes as representations of particular concepts is very helpful to display qualitative collected data in sociological studies. Interpretation or drawing conclusion involves making meaningful statements about how your data illustrates your topic of interest. This step involves drawing meaning from displayed data. Sociological inquiries drew meaning from the displayed data using a sociological orientation.

Commonly used approaches to analyze qualitative data includes grounded theory, contents analysis, conversation analysis, and discourse analysis. Each of these qualitative data analysis methods is different at least on the basis of their respective; background and philosophical foundation, unique characteristics, goals and rationale and data analysis process. Avoiding researcher subjective judgment and protecting subjects' privacy are the most important issues in doing qualitative data analysis.

\section{Reference}

Bateson, G. (1951). Psychiatric Thinking: An Epistemological Approach. International Journal of ruesh. 212-2

Bauer, M.W. (2000). Classical Content Analysis: A Review.' pp. 131-151 in Qualitative Researching with Text, Image and Sound. London: Sage Publications.

Berelson, B. (1952). Content Analysis in Communication Research. Glencoe, IL: Free Press.

Beigmann, J. (2004a). Conversation Analysis, in U. Flick,E.v. Kardorff, and I. Steinke (eds.), A Companion to Qualitative Research. London: SAGE Publications, pp. 296-302.

Bryman, A. (2001). Social Research Methods, Oxford: Oxford University Press

Bryman, A. and Burgess, R. (eds) (1994). Analyzing Qualitative Data, London: Routledge.

Cavanagh, S. (1997). Content Analysis: Concepts, Methods and Applications. Nurse Researcher, 4(3), 5-16.

Charmaz, K. (2006). Constructing Grounded Theory: A Practical Guide Through Qualitative Analysis. London: SAGE Publications.

Piergiorgio Corbetta. (2003). Social Research: Theory, Methods, and Techniques. London. Sage Publications.

Creswell, J. W. (2009). Research Design: Qualitative, Quantitative, and Mixed Methods Approaches (3rd ed.). Thousand Oaks, CA: Sage Publications, Inc.

Corbin, J., \& Strauss, A. (1998). Grounded Theory Research: Procedures, Canons, And Evaluative Criteria. Qualitative Sociology, 13(1), 3-21.

Crotty, M. (2003). The Foundations of Social Research: Meaning and Perspective in the Research Process (2nd ed.). London, UK: Sage Publications.

Crowley, B. P., \& Delfico, J. F. (1996). Content Analysis: A Methodology for Structuring and Analyzing Written Material. United States General Accounting Office (GAO), Program Evaluation and Methodology Division.

David, E. G. (n.d). Doing Research in the Real World. Los Angele: SAGE Publications

David, R. Felix P. (2003). Research Methods in Politics. Research Project. University of Liverpool Department Of Social And Environmental Studies.

Elo, S., \& Kyngäs, H. (2008). The Qualitative Content Analysis Process. Journal of Advanced Nursing, 62(1), 107-115.

Flick, U. (1994). Social Representations and the Social Construction of Everyday Knowledge: Theoretical and Methodological Queries, Social Science Information, 2:179-197.

Flick, U. (2009). An introduction to Qualitative Research. Fourth edition. London: SAGE.

Glaser, B., \& Strauss, A. (1967). The Discovery of Grounded Theory: Strategies For Qualitative Research. London, UK: Weidenfeld \& Nicholson.

Graneheim, U. H., \& Lundman, B. (2004). Qualitative Content Analysis in Nursing Research: Concepts, Procedures and Measures to Achieve Trustworthiness. Nurse Education Today, 24(2), 105-112.

Groat, L., \& Wang, D. (2002). Architectural Research Methods. New York, NY: Wiley \& Sons.

Have, P. Ten. (1999). Doing Conversation Analysis: A Practical Guide. London: SAGE.

Harry, B., Sturges, K. M., \& Klingner, J. K. (2005). Mapping the Process: An Exemplar Of Process and Challenge in Grounded Theory. Educational Researcher, 34(2), 3-13.

Hsieh, H-F., \& Shannon, S. E. (2005). Three Approaches to Qualitative Content Analysis. Qualitative Health Research, 15(9), 1277-1288.

Huberman, A., \& Miles, M., (1994). Qualitative data analysis (2 ${ }^{\text {nd }}$ ed.). Thousand Oaks, CA: Sage Publications. Jennifer Mason. (2002). Qualitative Researching. $2^{\text {nd }}$ edition. SAGE Publications. London.

Kracauer, S. (1952). The Challenge of Qualitative Content Analysis. Public Opinion Quarterly, 16, 631-642.

Kuhn, T. (1970). The Structure of Scientific Revolutions. ( $2^{\text {nd }}$ Ed.). Chicago, University Of Chicago Press.

Mayring, P. (2000). Qualitative Content Analysis, Forum: Qualitative Social Research, 1 (2). Qualitative Research. 
Net/Fqs.

Parker, I. (2004). Discourse Analysis, in U. Flick, E.v. Kardorff, and I. Steinke (eds.), A Companion to Qualitative Research. London: SAGE. pp. 308-312.

Priest, H., Roberts, P., \& Woods, L. (2002). An Overview of Three Different Approaches To The Interpretation of Qualitative Data. Part 1: Theoretical issues. Nurse Researcher, 10(1), 30.

Saldana, J. (2009). The Coding Manual for Qualitative Researchers. Thousand Oaks, CA: Sage Publications.

Saldana, J., (2013). The Coding Manual For Qualitative Researchers, 2nd edn., Sage, London.

Schegloff, E. and Sacks, H. (1974). Opening up Closings, in R. Turner (ed.), Ethnomethodology. Harmondsworth: Penguin, pp. 233-264.

Schreier, M. (2012). Qualitative Content Analysis in Practice. Thousand Oaks, CA: Sage.

Scott D. \& Usher R. (2004). Researching Education: Data, Methods, and Theory In Educational Inquiry. New York: Continuum.

Scotland J. (2012). Exploring the Philosophical Underpinnings of Research: Relating Ontology And Epistemology to the Methodology and Methods Of The Scientific, Interpretive, And Critical Research Paradigms. English Language Teaching; 5 (9)

Streubert, H. J., \& Carpenter, D. R. (1995). Qualitative Research in Nursing: Advancing The Humanistic Imperative. Philadelphia, PA: Lippincott.

Strauss, A., \& Corbin, J. (1990). Basics of Qualitative Research. Newbury Park, CA: Sage Publications.

Strauss, A., \& Corbin, J. (1994). Grounded Theory Methodology. In N. Denzin \& Y. Lincoln (Eds.), Handbook of Qualitative Research (pp. 273-285). Thousand Oaks, CA: Sage.

Silverman, D. (1993). Interpreting Qualitative Data: Methods for Analyzing Talk, Text and Interaction, London: Sage

Suddaby, R. (2006). From The Editors: What Grounded Theory Is Not. Academy Of Management Journal ARCHIVE, 49(4), 633-642. 